\title{
Galectin-1 Controls Cardiac Inflammation and Ventricular Remodeling during Acute Myocardial Infarction
}

\author{
Ignacio M. Seropian, ${ }^{* \dagger}$ Juan P. Cerliani, ${ }^{\ddagger}$ Stefano Toldo, ${ }^{\star \S}$ Benjamín W. Van Tassell, ${ }^{\star \dagger}$ Juan M. Ilarregui, ${ }^{\ddagger}$ Germán E. González, \\ Mirian Matoso, ${ }^{\circledR}$ Fadi N. Salloum, ${ }^{*}$ Ryan Melchior, ${ }^{* \dagger}$ Ricardo J. Gelpi, ${ }^{\Uparrow}$ Juan C. Stupirski, ${ }^{\ddagger}$ Alejandro Benatar, \\ Karina A. Gómez, "Celina Morales, " Antonio Abbate, ${ }^{\star \S}$ and Gabriel A. Rabinovich ${ }^{\ddagger * *}$
}

\begin{abstract}
From the VCU Pauley Heart Center, ${ }^{*}$ the School of Pharmacy, ${ }^{\dagger}$ and the VCU Victoria Johnson Center, ${ }^{\S}$ Virginia Commonwealth University, Richmond, Virginia; the Laboratory of Immunopathology, ${ }^{\ddagger}$ Institute of Biology and Experimental Medicine (IBYME), and the Institute of Research in Genetic Engineering and Molecular Biology (INGEBI)," National Scientific and Technical Research Council (CONICET), Buenos Aires, Argentina; and the Institute of Cardiovascular Physiopathology, "Faculty of Medicine, and Department of Biological Chemistry, ** Faculty of Exact and Natural Sciences, University of Buenos Aires, Buenos Aires, Argentina
\end{abstract}

\author{
Accepted for publication \\ September 29, 2012. \\ Address correspondence to \\ Gabriel A. Rabinovich, Ph.D., \\ Laboratorio de Inmunopatolo- \\ gía, Instituto de Biología y \\ Medicina Experimental, Consejo \\ Nacional de Investigaciones \\ Científicas y Técnicas, Vuelta de \\ Obligado 2490, C1428 Buenos \\ Aires, Argentina, or Antonio \\ Abbate, M.D., Ph.D., \\ VCU Pauley Heart Center, \\ Virginia Commonwealth \\ University, 1200 East Broad \\ Street-West Hospital, \\ P.O. Box 980281, Richmond, \\ VA 23298-0281. E-mail: \\ gabyrabi@gmail.com or \\ aabbate@mcvh-vcu.edu.
}

\begin{abstract}
Galectin-1 (Gal-1), an evolutionarily conserved $\beta$-galactoside-binding lectin, plays essential roles in the control of inflammation and neovascularization. Although identified as a major component of the contractile apparatus of cardiomyocytes, the potential role of Gal-1 in modulating heart pathophysiology is uncertain. Here, we aimed to characterize Gal-1 expression and function in the infarcted heart. Expression of Gal-1 was substantially increased in the mouse heart 7 days after acute myocardial infarction (AMI) and in hearts from patients with end-stage chronic heart failure. This lectin was localized mainly in cardiomyocytes and inflammatory infiltrates in peri-infarct areas, but not in remote areas. Both simulated hypoxia and proinflammatory cytokines selectively up-regulated Gal-1 expression in mouse cardiomyocytes, whereas anti-inflammatory cytokines inhibited expression of this lectin or had no considerable effect. Compared with their wild-type counterpart, Gal-1-deficient (Lgals ${ }^{-/-}$) mice showed enhanced cardiac inflammation, characterized by increased numbers of macrophages, natural killer cells, and total T cells, but reduced frequency of regulatory T cells, leading to impaired cardiac function at baseline and impaired ventricular remodeling 7 days after nonreperfused AMI. Treatment of mice with recombinant Gal-1 attenuated cardiac damage in reperfused AMI. Taken together, our results indicate a protective role for Gal-1 in normal cardiac homeostasis and postinfarction remodeling by preventing cardiac inflammation. Thus, Gal-1 treatment represents a potential novel strategy to attenuate heart failure in AMI. (Am J Pathol 2013, 182: 29-40; http://dx.doi.org/ 10.1016/j.ajpath.2012.09.022)
\end{abstract}

Acute myocardial infarction (AMI) is among the most common causes of death worldwide. ${ }^{1}$ Improvements in therapies over the past decades have led to a significant decrease in early mortality after AMI. ${ }^{2}$ Despite new therapies, however, those who survive the initial ischemic event are at higher risk of developing heart failure. ${ }^{3}$ Thus, there is an urgent need to find novel therapies to ameliorate cardiac remodeling after AMI and to prevent heart failure.

Lectin-glycan interactions have recently emerged as regulators of a wide range of physiological and pathological processes. ${ }^{4}$ Galectin-1 (Gal-1), a prototype member of a family of highly conserved $\beta$-galactoside-binding lectins, modulates cellular signaling, proliferation, and survival and plays critical roles in the control of acute and chronic inflammation and neovascularization. ${ }^{5-10}$ This homodimeric $\beta$-galactoside-binding protein, composed of $14.5-\mathrm{kDa}$ subunits, can control cellular processes through modulation of intracellular signaling pathways or through extracellular

Supported in part by an American Heart Association Scientist development grant (national) (A.A.) and by the Argentinean National Agency for Promotion of Science and Technology, University of Buenos Aires, and Fundación Sales (G.A.R.).

I.M.S. and J.P.C. contributed equally to this work.

A.A. and G.A.R. contributed equally as supervisors to this work.

Current address of I.M.S., Department of Cardiology, FLENI Foundation, C1428, Buenos Aires, Argentina. 
mechanisms involving recognition and cross-linking on $\mathrm{N}$ and $O$-glycans on cell-surface glycoconjugates. ${ }^{4-8}$

Previous studies have identified Gal-1 as part of the hypoxia-regulated transcriptome ${ }^{11}$ and as a major component of the contractile apparatus in cardiomyocytes, ${ }^{12}$ suggesting a potential role of this lectin in modulating cardiac function and postinfarction remodeling. We undertook the present study to characterize the role of this glycanbinding protein in a mouse model of AMI and also its regulated expression in patients with heart failure. Our results show a protective role of Gal-1 in normal cardiac homeostasis and postinfarction remodeling through modulation of the inflammatory response, suggesting potential novel strategies to attenuate heart failure in AMI.

\section{Materials and Methods}

\section{Mice}

Animal studies were conducted in accordance with the Guide for the Care and Use of Laboratory Animals, 8th Edition (2011). Protocols were approved by the Virginia Commonwealth University Institutional Animal Care and Use Committee. Mice with genetic deletion of the gene encoding Gal-1 (Lgals1 ${ }^{-/}$) or age- and sex-matched wild-type (WT) mice with equivalent genetic background (C57BL/6) were acquired from the Jackson Laboratory (Bar Harbor, ME). Adult male outbred ICR (CD-1) mice were acquired from Harlan Sprague Dawley (Indianapolis, IN).

\section{Experimental AMI}

Experimental AMI was performed via permanent coronary artery ligation, as described previously. ${ }^{13-15}$ Briefly, mice were orotracheally intubated under anesthesia (pentobarbital $70 \mathrm{mg} / \mathrm{kg}$ ) and placed in the right lateral decubitus position. Mice then underwent left thoracotomy, pericardiectomy, and ligation of the proximal left coronary artery with a 7-0 silk suture. In sham surgery, animals underwent the same surgical procedure, but without coronary artery ligation $(n=6)$. This experimental model involves marked cardiac dilation and severe left ventricular (LV) systolic dysfunction.

An additional group of CD-1 mice underwent surgical transient coronary artery ligation for 30 minutes followed by reperfusion to evaluate the effects of Gal-1 in a clinically relevant model in which exogenous Gal-1 was given at the time of reperfusion. After surgery, mice in the ischemiareperfusion protocol were randomly assigned to treatment with recombinant Gal-1 (rGal-1) $(n=6)$ or control saline $(n=6)$. Preadsorbed rGal-1 was administered intraperitoneally at a single dose of $3 \mathrm{mg} / \mathrm{kg}(\sim 100 \mu \mathrm{g}$ per mouse) 3 minutes before reperfusion, to ensure considerable plasmatic levels at the time of reperfusion. This dose of rGal-1 was shown to be effective in experimental models of autoimmune inflammation., ${ }^{9,10}$

\section{Doppler Echocardiography}

Doppler echocardiography was performed using a Vevo770 imaging system (VisualSonics, Toronto, ON, Canada) and a $30-\mathrm{MHz}$ probe. The transducer was positioned on the left anterior side of the chest. The heart was first imaged in the twodimensional mode in the short-axis view of the left ventricle. M-mode images were then obtained at the level of the papillary muscles below the mitral valve tip, in accordance with American Society of Echocardiography recommendations. ${ }^{16}$ The M-mode cursor was positioned perpendicular to the anterior and posterior wall to measure LV end-diastolic diameter (LVEDD), LV end-systolic diameter (LVESD), anterior wall diastolic thickness (AWDT), anterior wall systolic thickness (AWST), posterior wall diastolic thickness (PWDT), and posterior wall systolic thickness (PWST). LV fractional shortening (LVFS) was calculated as follows: LVFS = [(LVEDD - LVESD)/LVEDD] $\times 100$. Percentage of change from baseline to 7 days was calculated for each variable as [ $(7$ days - baseline $) /$ baseline $] \times 100$. The investigator (A.A.) performing and reading the echocardiogram was masked to the treatment allocation.

Production of rGal-1, Anti-Gal-1 Polyclonal Antibody, and Gal-1-Specific shRNA

rGal-1 was produced and purified essentially as described previously. ${ }^{9,10}$ LPS content of the purified samples $(<60 \mathrm{ng} / \mathrm{mg})$ was tested using a gel-clot Limulus test (Associates of Cape Cod, Falmouth, MA). Gal-1-specific shRNA and scrambled shRNA were designed and cloned into the pSIREN-RetroQ vector (Clontech Laboratories, Palo Alto, CA) as described previously. ${ }^{17}$ A polyclonal anti-Gal-1 IgG was generated and used as described previously. ${ }^{9}$

\section{In Vitro Cell Cultures, Hypoxia Induction, and Cytokine Regulation}

The HL-1, an immortalized adult murine cardiomyocyte cell line, was cultured in Claycomb medium (Sigma-Aldrich, St. Louis, MO) as described previously. ${ }^{18}$ To study the effects of hypoxia on Gal-1 expression in cardiomyocytes, HL-1 cells $\left(5 \times 10^{5}\right.$ cells/well $)$ were cultured in 24 -well plates, placed in a modular incubator chamber (Billups-Rothenberg, Del Mar, CA), and flushed at 2 psi $(\sim 14 \mathrm{kPa})$ for 10 minutes with a mixture of $1 \% \mathrm{O}_{2}, 5 \% \mathrm{CO}_{2}$, and $94 \% \mathrm{~N}_{2}$. The chamber was sealed and placed in a $37^{\circ} \mathrm{C}$ incubator for 18 hours. Controls of normoxia were placed in the same incubator at $20 \% \mathrm{O}_{2}$. In addition, $\mathrm{HL}-1$ cells were cultured for 18 hours in the absence or presence of different cytokines (all from R\&D Systems, Minneapolis, MN), including IFN- $\gamma(50 \mathrm{ng} / \mathrm{mL})$, TNF- $\alpha(20 \mathrm{ng} / \mathrm{mL}), \mathrm{IL}-1 \beta(1 \mathrm{ng} / \mathrm{mL})$, 
IL-6 (2 ng/mL), IL-17 (5 ng/mL), TGF- $\beta 1$ (5 ng/mL), and IL-10 $(50 \mathrm{ng} / \mathrm{mL})$. After this incubation period, cells were processed for real-time quantitative RT-PCR (RT-qPCR) and immunoblot analysis. Supernatants were collected and Gal-1 secretion was assessed by enzyme-linked immunosorbent assay (ELISA).

\section{Cell Death Assays}

To assess the role of Gal-1 in hypoxia-induced cardiomyocyte apoptosis, HL-1 cells were cultured in six-well plates, placed in a modular incubator chamber to induce hypoxia, and then incubated for 18 hours with or without rGal-1 $(10 \mu \mathrm{g} / \mathrm{mL})$. Apoptotic cells were identified by staining with fluorescein isothiocyanate-conjugated annexin $\mathrm{V}$ (BD Biosciences, San Jose, CA) according to the manufacturer's instructions and were analyzed on a FACSAria flow cytometer (BD Biosciences) as described previously. ${ }^{10}$ HL-1 cells were transduced with a retroviral vector containing Gal-1-specific shRNA or scrambled control vector using Lipofectamine 2000 transfection reagent according to the manufacturer's instructions (Invitrogen; Life Technologies, Carlsbad, CA). After 24 hours, cells were starved and subjected to hypoxia and cell death assays.

\section{Primary Cultures of Cardiomyocytes}

Primary culturing of cardiomyocytes was performed as described previously, ${ }^{19}$ with slight modifications. Briefly, in aseptic conditions, hearts from neonatal WT and ggals $^{-1-}$ C57BL/6 mice of up to 3 days of age were removed and rinsed in Hanks' balanced salt solution (Gibco; Life Technologies) supplemented with $1 \%$ glucose and then were minced into small pieces. Sedimented tissue was resuspended in Hanks' balanced salt solution-glucose containing trypsin $(0.25 \% \mathrm{w} / \mathrm{v})$ (Gibco; Life Technologies), and the tissue was shaken for 12 minutes at $37^{\circ} \mathrm{C}$. The reaction was stopped with Hanks' balanced salt solution-glucose plus $10 \%$ fetal calf serum (Gibco; Life Technologies), and dislodged cells were recovered by centrifugation at $200 \times g$ for 10 minutes. This procedure was repeated three times. The product of the first digestion was discarded; the remaining cells were pooled, resuspended in Dulbecco's modified Eagle's medium-F12 medium (Gibco; Life Technologies) containing $20 \%$ fetal calf serum, and plated in tissue culture dishes at $37^{\circ} \mathrm{C}$ for 2 hours under a water-saturated atmosphere of $5 \% \mathrm{CO}_{2}$, to exclude adherent nonmuscle cells. Nonadherent cells were then cultured as monolayers on culture dishes treated with $0.1 \%$ gelatin at a density of 100,000 cells $/ \mathrm{cm}^{2}$ for 4 days in Dulbecco's modified Eagle's medium-F12 supplemented with $20 \%$ fetal calf serum. Cells, exhibiting a spontaneous basal pulsation rate of 120 beats/minute, were then changed to Dulbecco's modified Eagle's medium-F12 supplemented with $10 \%$ fetal calf serum for 1 hour, and the beating rate was measured in clusters of synchronically beating cardiomyocytes (10 fields) both at baseline and 2 hours after exposure to rGal-1 $(10 \mu \mathrm{g} / \mathrm{mL})$. At the end of each measurement, isoproterenol $(1 \mu \mathrm{mol} / \mathrm{L})$ was added, to further evaluate the chronotropic response.

\section{RT-qPCR}

RT-qPCR was performed with SYBR Green PCR master mix and ABI PRISM 7500 sequence detection software (both from Life Technologies, Foster City, CA). The following primers were used: mouse Gal-1, forward $5^{\prime}$-TGAACCTGGGAAAAGACAGC-3' ${ }^{\prime}$ and reverse $5^{\prime}$-TCAGCCTGGTCAAAGGTGAT- ${ }^{\prime}$; mouse GAPDH forward 5'-CCAGAACATCATCCCTGCAT-3' and reverse 5'-GTTCAGCTCTGGGATGACCTT- $3^{\prime}$.

\section{ELISA}

Soluble Gal-1 was determined using an in-house ELISA. Briefly, high-binding 96-well microplates (Costar; Corning Life Sciences, Tewksbury, MA) were coated with capture antibody $(2 \mu \mathrm{g} / \mathrm{mL}$ purified rabbit anti-Gal-1 polyclonal $\mathrm{IgG})$ in $0.1 \mathrm{~mol} / \mathrm{L}$ sodium carbonate, $\mathrm{pH}$ 9.5. After incubation for 18 hours at $4^{\circ} \mathrm{C}$, wells were rinsed three times with wash buffer $(0.05 \%$ Tween-20 in PBS) and incubated for 1 hour with blocking solution ( $2 \%$ bovine serum albumin in PBS). Samples and standards $(100 \mu \mathrm{L})$ were diluted in $1 \%$ bovine serum albumin and incubated for 18 hours at $4{ }^{\circ} \mathrm{C}$. Plates were then washed and incubated with $100 \mathrm{ng} / \mathrm{mL}$ biotinylated detection antibody (purified rabbit anti-Gal-1 polyclonal $\mathrm{IgG}$ ) for 1 hour. Plates were rinsed three times before addition of horseradish peroxidaselabeled streptavidin $(0.33 \mu \mathrm{g} / \mathrm{mL}$; Sigma-Aldrich) for 30 minutes. After a washing, $100 \mu \mathrm{L}$ of TMB solution $(0.1 \mathrm{mg} / \mathrm{mL}$ tetramethylbenzidine and $0.06 \% \mathrm{H}_{2} \mathrm{O}_{2}$ in citrate-phosphate buffer, $\mathrm{pH}$ 5.0) was added to the plates. The reaction was stopped by adding $4 \mathrm{~mol} / \mathrm{L} \mathrm{H}_{2} \mathrm{SO}_{4}$. Optical densities were determined at $450 \mathrm{~nm}$ in a Multiskan MS microplate reader (Thermo Scientific, Pittsburgh, PA). A standard curve ranging from 2.5 to $160 \mathrm{ng} / \mathrm{mL} \mathrm{rGal-1}$ was run in parallel.

\section{Immunoblot Analysis and Immunohistochemistry}

After experimental AMI without reperfusion, CD-1 mice were sacrificed at 24 hours, 72 hours, 7 days, or 15 days after surgery to determine cardiac Gal-1 expression by immunoblot analysis. Sham-operated animals were used as controls. The harvested hearts were washed in ice-cold PBS, atria were removed, and ventricles were snap-frozen in liquid nitrogen and stored at $-80^{\circ} \mathrm{C}$. Collected heart samples and HL-1 cardiomyocyte cultures were homogenized in ice-cold radioimmunoprecipitation assay buffer (Sigma-Aldrich) in the presence of a protease inhibitor cocktail (Sigma-Aldrich). The homogenates were centrifuged at $16,000 \times g$ for 20 minutes 
at $4{ }^{\circ} \mathrm{C}$, and the supernatants were recovered and quantified using Bradford's protein assay (Sigma-Aldrich). Total protein extracts $(60 \mu \mathrm{g})$ from each sample were resolved by SDSPAGE on $15 \%$ polyacrylamide gels and transferred onto nitrocellulose membranes. rGal-1 (30 ng) was used as a positive control. The membranes were subsequently incubated with a rabbit anti-Gal-1 polyclonal antibody (dilution $1: 500)^{9}$ or a mouse monoclonal antibody for $\beta$-actin (clone C2; Sigma-Aldrich) to control for equal loading. Blots were then incubated with horseradish peroxidase-conjugated secondary antibodies (Bio-Rad Laboratories, Hercules, CA) and developed using Immobilon chemiluminescent horseradish peroxidase substrate (Millipore, Billerica, MA). Protein bands were analyzed with ImageJ version 1.440 analysis software (NIH, Bethesda, MD).

Another group of mice was also sacrificed 72 hours after AMI, to evaluate distribution of Gal-1 in mouse hearts by immunohistochemistry. After sacrifice, hearts were extracted and fixed in $10 \%$ formalin for at least 72 hours. A transverse section of the median third of the left ventricle was cut and embedded in paraffin. Finally, slides with sections $5-\mu \mathrm{m}$ thick were processed for immunohistochemical analysis. Identification of Gal-1 was performed using a rabbit anti-Gal-1 polyclonal antibody (dilution 1:200) and a horseradish peroxidase-conjugated anti-rabbit IgG (dilution 1:1000; Amersham; GE Healthcare, Little Chalfont, UK) as a secondary antibody, as described ${ }^{17}$ using a Vectastain Elite $\mathrm{ABC}$ kit (Vector Laboratories, Burlingame, CA).

Heart samples from 10 patients with end-stage heart failure undergoing cardiac surgery for either LV assisting device collocation or heart transplantation at Pauley Heart Center (Virginia Commonwealth University, Richmond) from 2004 to 2010, as well as two control heart samples from autopsies of patients without any cardiac condition, were processed for immunohistochemistry. A small part of the left ventricle, including all layers of the cardiac tissue (endocardium, myocardium, and epicardium), was fixed in formalin for at least 72 hours. Hearts were then paraffinembedded and cut into 5- $\mu \mathrm{m}$ slices for histology processing. Immunohistochemistry was performed as described above, except that the anti-Gal-1 polyclonal antibody was used at a dilution of 1:400. To assess nonspecific binding of the secondary antibody, samples were incubated without primary antibody and processed as described above. Patient characteristics were obtained retrospectively from chart review. An expert pathologist (M.M.) masked to patient characteristics performed a semiquantitative measurement of Gal-1 stain in cardiomyocytes, interstitium, and inflammatory cells.

The studies were approved by the Institutional Review Board of Virginia Commonwealth University (VCU).

\section{Immunofluorescence Staining}

The inflammatory response was evaluated in hearts from WT or Lgals1 ${ }^{-/-}$mice at baseline (before surgery), in sham-operated mice, and 7 days after AMI. Briefly, hearts were embedded in optimal cutting temperature compound, and immunofluorescence staining was performed with the following primary antibodies: rat anti-CD31 (Mec13.3; 1:100; BD Biosciences), mouse anti-F4/80 (BM8; 1:100; eBioscience, San Diego, CA), rat anti-B220 (RA3-6B2; 1:100; BD Pharmingen, San Diego, CA), rat anti-NK1.1 (PK136; 1:200; BD Pharmingen), rabbit anti-MMP-9 (sc10737; 1:200; Santa Cruz Biotechnology, Santa Cruz, CA), and rabbit anti-FoxP3 (FJK-16s; 1:200; eBioscience). The number of infiltrating cells in heart sections was expressed as mean \pm SEM of three independent experiments with five animals per group. Sham-operated mice and uninjured (baseline) mice were also evaluated. Heart histopathology was assessed by H\&E staining, and collagen was evaluated by Sirius Red staining (Sigma-Aldrich).

\section{Statistical Analysis}

We used analysis of variance for multiple comparisons with post hoc $t$-test to examine group differences. For comparisons of interval changes between multiple groups, we used random-effects analysis of variance for repeated measures to determine the main effect of time, group, and time-by-group interactions. Statistical differences were considered significant if $P$ values were $<0.05$.

\section{Results}

\section{Gal-1 Is Dynamically Regulated in the Mouse Heart during Experimental AMI}

To study the role of Gal-1 in cardiac pathophysiology, we first investigated the expression and distribution of this endogenous lectin in cardiac tissue of CD-1 mice after AMI. Gal-1 was expressed, although at low levels, in hearts from sham-operated mice (Figure 1A). In experimental nonreperfused AMI, cardiac Gal-1 expression was unchanged 24 hours after coronary ligation, whereas a sevenfold higher expression was observed after 7 days, compared with shamoperated mice (Figure 1A). Gal-1 was distributed mainly in the peri-infarct area, with minimal or no staining in the remote myocardium, and was expressed primarily by cardiomyocytes, mononuclear cells, and polymorphonuclear neutrophils infiltrating the infarct region (Figure 1B). These data suggest a dynamic regulation of Gal-1 expression and distribution in mouse heart after AMI and thus suggest a potential role of Gal-1 in regulating cardiac pathophysiology.

\section{Gal-1 Expression Is Up-Regulated in Patients with End-Stage Heart Failure}

Given its marked regulation in the mouse heart after AMI, we next sought to examine the expression of Gal-1 in heart samples from patients with end-stage heart failure and from 
A
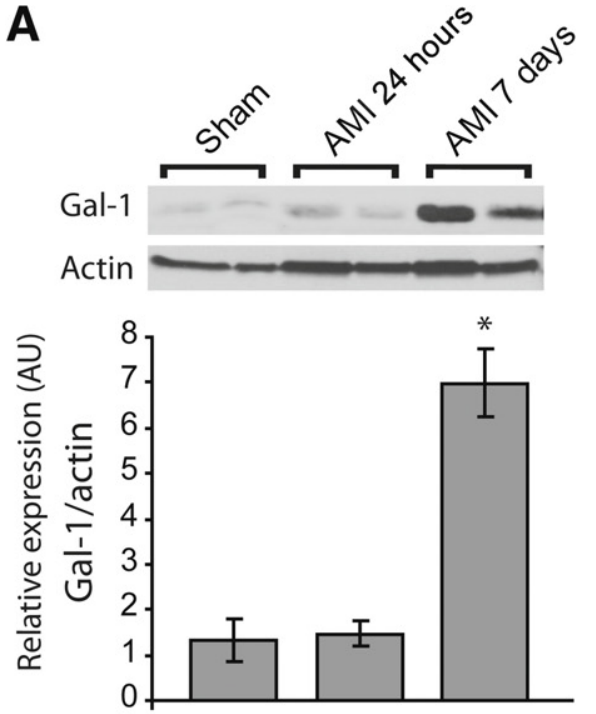

B

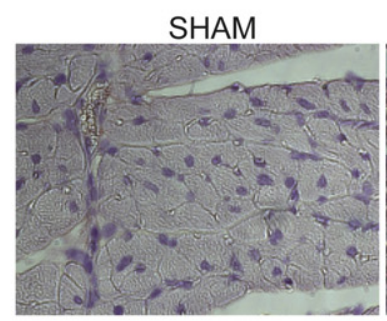

Myocytes peri-infarct area Myocytes remote area

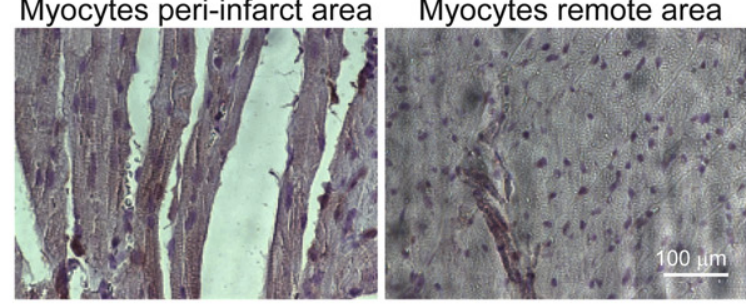

\section{Control patient}

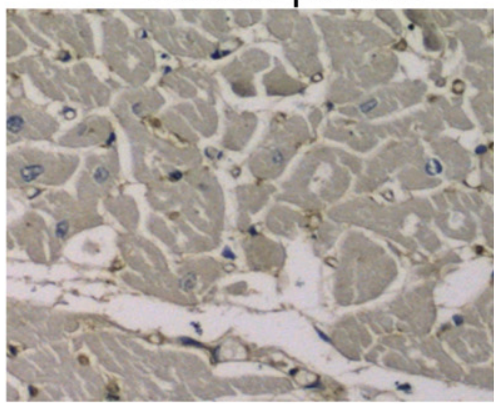

Non-ischemic cardiomyopathy

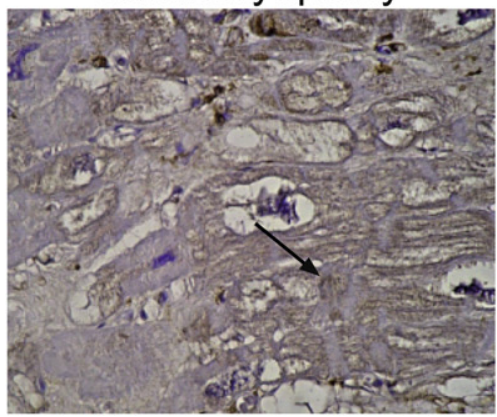

Control patient

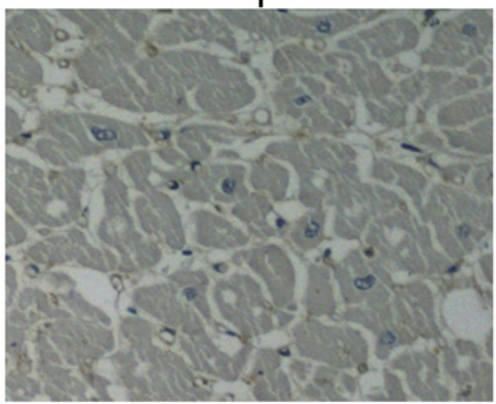

Ischemic cardiomyopathy

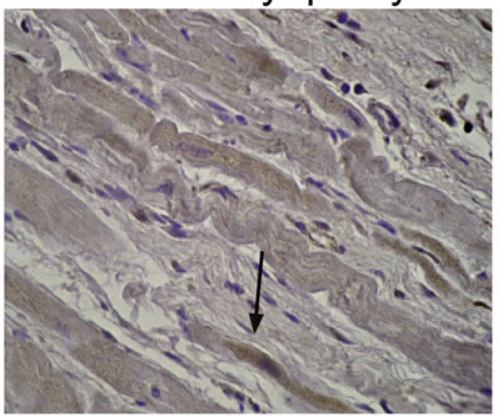

Control patient

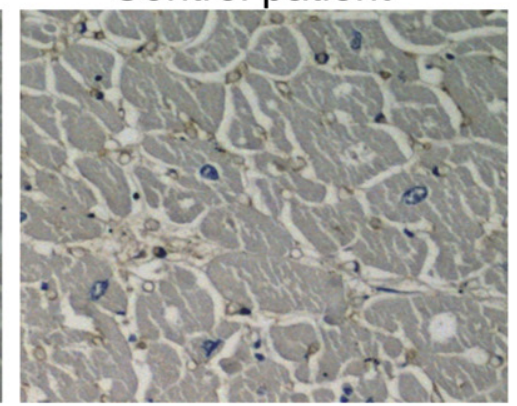

Adriamycine-induced cardiomyopathy

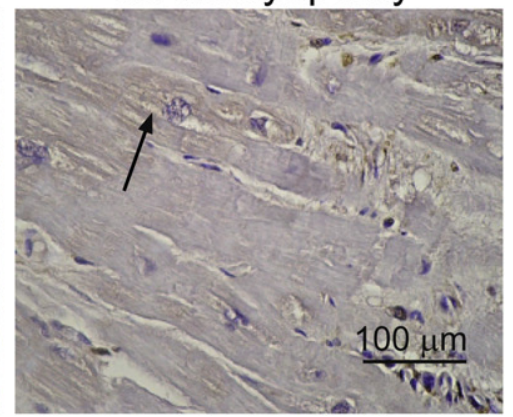

Figure 1 Regulation of Gal-1 expression in the mouse heart after AMI and in cardiac tissue from patients with end-stage chronic heart failure. A: Immunoblot analysis of Gal-1 expression in total heart lysates from sham-operated CD-1 mice or after experimental AMI. Immunoreactive protein bands were semiquantified by densitometry and expressed in arbitrary units (AU) relative to $\beta$-actin. B: Representative images from immunohistochemistry of Gal- 1 in mouse heart 72 hours after AMI and in sham-operated mice. Gal-1 is highly expressed in cardiomyocytes in the peri-infarct area of mice after AMI, but is absent in the remote area (septum) of these mice and after sham surgery. Representative tissues from each group are shown. C: Immunohistochemistry of Gal1 in human cardiac tissue revealed Gal- $1^{+}$cardiomyocytes (arrows) in patients with end-stage chronic heart failure, but not in tissue from control patients who died from noncardiac causes. Clinical features of patients and magnitude of Gal-1 expression are presented in Table 1. Data are expressed as means \pm SEM and are representative of three independent experiments. $n=6$ mice per group. ${ }^{*} P<0.05$. Scale bar $=100 \mu$ m. Original magnification, $\times 400$.

control individuals (Table 1). Gal-1 was considerably expressed in cardiomyocytes from patients with heart failure, including those with ischemic cardiomyopathy, nonischemic cardiomyopathy, and Adriamycin (doxorubicin)-induced cardiomyopathy, but was absent or barely detectable in cardiac tissue from control individuals (Figure 1C and Table 1). Gal-1 was abundantly distributed in myocytes and interstitium of cardiac tissue from patients with heart failure and was expressed at moderate levels in inflammatory infiltrates (Table 1). Remarkably, up-regulation of Gal-1 was 
Table 1 Description, Clinical Features, and Gal-1 Expression in Cardiac Tissue from Control Individuals and Heart Failure Patients

\begin{tabular}{|c|c|c|c|c|c|c|c|c|}
\hline \multirow[b]{2}{*}{ Patient ID no. } & \multirow[b]{2}{*}{ Age (years) } & \multirow[b]{2}{*}{ Sex } & \multirow[b]{2}{*}{ Ethnicity } & \multirow[b]{2}{*}{ LVEF, \% } & \multirow[b]{2}{*}{ Ischemic } & \multicolumn{3}{|c|}{ Gal-1 expression* } \\
\hline & & & & & & Myocytes & Interstitium & Inflammatory infiltrate \\
\hline \multicolumn{9}{|l|}{ Controls } \\
\hline 13 & & & W & & & 0 & + & No cells \\
\hline \multicolumn{9}{|l|}{ Heart failure } \\
\hline 1 & 66 & $\mathrm{~F}$ & W & 20 & Yes & ++ & ++ & + \\
\hline 11 & 58 & M & W & 15 & Yes & +++ & +++ & + \\
\hline 3 & 19 & M & B & 10 & No & ++ & +++ & + \\
\hline 4 & 31 & M & W & 20 & No & ++ & +++ & + \\
\hline 5 & 48 & M & W & 18 & No & +++ & +++ & ++ \\
\hline 8 & 56 & $\mathrm{~F}$ & B & 20 & No & +++ & +++ & + \\
\hline
\end{tabular}

*Gal-1 expression was scored as follows: 0 , no stain; + , mild stain; ++ , moderate stain; +++ , intense stain.

F, female; M, male; B, black; LVEF; left ventricular ejection fraction; W, white.

evident in heart tissue from all patients with heart failure, irrespective of the cause of the disease, percentage of LV ejection fraction (LVEF\%), or age, ethnicity, and sex (Table 1).

\section{Hypoxia and Proinflammatory Cytokines Up-Regulate Expression and Secretion of Gal-1 by Cardiomyocytes}

Given the prevalence of hypoxic microenvironments in infarcted hearts, ${ }^{3}$ we then investigated expression of this lectin in cultured cardiomyocytes exposed to hypoxic or normoxic conditions. Exposure of HL-1 cardiomyocytes to experimental hypoxia resulted in a substantial increase in Gal-1 expression, compared with cells cultured under normal oxygen pressure (Figure 2A). Given the pivotal role of cytokines in modulating the response to AMI during ischemia ${ }^{15}$ we next evaluated whether Gal-1 expression and secretion were differently regulated by proinflammatory or anti-inflammatory cytokines in cardiomyocytes. Remarkably, IL-17 was the most potent stimulus capable of up-regulating Gal-1 expression both at the mRNA and protein levels and augmenting its secretion by cardiomyocytes (Figure 2, B-D). Exposure to IL-6 induced a considerable up-regulation of Gal-1 mRNA and protein expression, but did not significantly alter its secretion (Figure 2, B-D). Exposure to TNF- $\alpha$ led to a considerable increase in Gal-1 mRNA expression and secretion, whereas exposure to IFN- $\gamma$ did not increase Gal-1 transcript, but substantially augmented Gal-1 protein expression and secretion. Of note, exposure to IL- $1 \beta$, a cytokine that is critically involved in the pathogenesis of AMI, had no considerable effect on the expression or secretion of this lectin. On the other hand, anti-inflammatory or tolerogenic cytokines such as TGF- $\beta 1$ or IL- 10 showed a trend toward inhibition of Gal-1 expression but had no considerable effects on Gal-1 secretion (Figure 2, B-D). Taken together, these data indicate that hypoxic and proinflammatory (Th17 and Th1) microenvironments, commonly observed during AMI, contribute to augmenting Gal-1 expression and/or secretion by cardiomyocytes, possibly as a homeostatic mechanism to temper cardiac inflammatory responses.

\section{Endogenous or Exogenous Gal-1 Does Not Alter Hypoxia-Driven Apoptosis or Heart Rate of Cardiomyocytes in Vitro}

Given the higher expression of Gal-1 in the peri-infarct area and its up-regulation in hypoxic microenvironments, we next sought to examine the role of endogenous and exogenous Gal-1 in cardiomyocyte physiology in vitro. Because Gal-1 modulates the survival of a variety of cell types, ${ }^{4,5,8}$ we first studied the effects of Gal-1 in hypoxia-driven cardiomyocyte apoptosis. We could find no significant modulation of hypoxia-driven apoptosis when cardiomyocytes were exposed to rGal-1 or when Gal-1 was silenced on transfection with Gal-1-specific shRNA (Figure 2E), suggesting lack of effect of endogenous or exogenous Gal-1 on cardiomyocyte viability.

Acute decompensated heart failure is associated with increased heart rate, an independent predictor of adverse events. ${ }^{20}$ To test whether Gal-1 could directly affect heart rate leading to systolic dysfunction (tachycardia-induced cardiomyopathy), we tested the effects of exogenous or endogenous Gal-1 in primary cultured cardiomyocytes isolated from WT mice or from mice lacking the Gal-1 gene (Lgals $1^{-1-}$ ). Primary cultured cardiomyocytes from newborn WT or $\mathrm{Lgals}^{-1-}$ mice showed similar beating rate at baseline or after challenge with isoproterenol, a $\beta$ sympathomimetic that functions as a heart stimulant (Figure 2, F-H). Moreover, addition of rGal-1 did not alter 


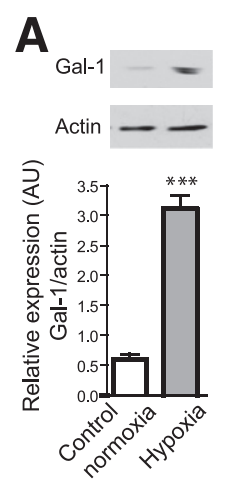

B

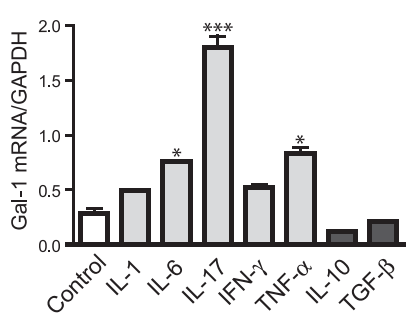

C
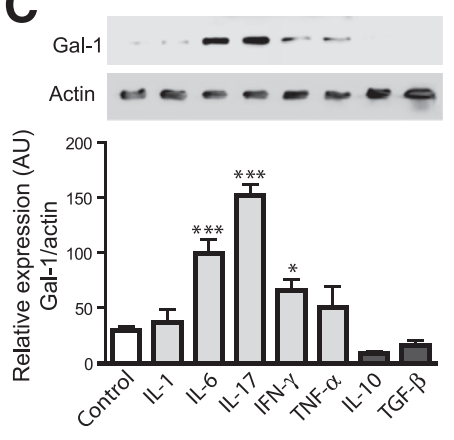

D
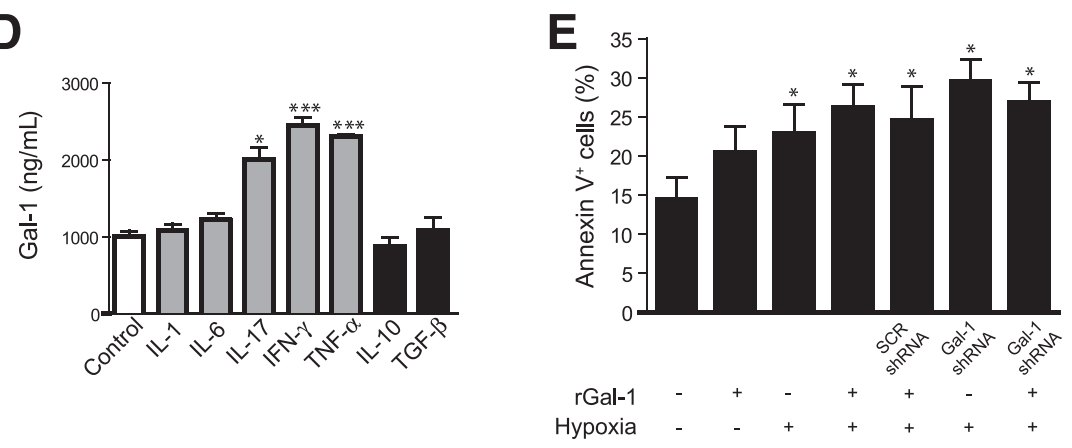

$\mathbf{F}$

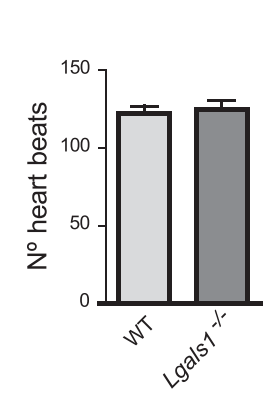

G

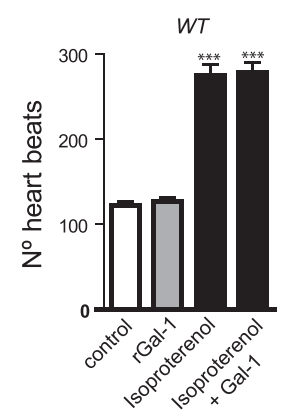

H

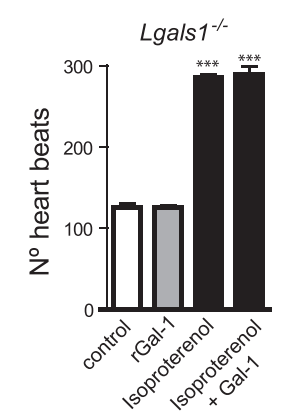

Figure 2 Regulation of Gal-1 expression and function in cardiomyocytes. A: Immunoblot analysis of Gal-1 expression in total cell lysates from HL-1 cardiomyocytes exposed to hypoxic or normoxic conditions. Immunoreactive protein bands were semiquantified by densitometry and expressed in arbitrary units (AU) relative to $\beta$-actin. B: RT-qPCR analysis of Gal-1 mRNA expression in HL-1 cells cultured in the absence or presence of proinflammatory (IL-1 $\beta$, IL-6, IL-17, IFN- $\gamma$, TNF- $\alpha$ ) or anti-inflammatory (TGF- $\beta 1, \mathrm{IL}-10$ ) cytokines for 18 hours. Data are expressed relative to GAPDH mRNA. C: Immunoblot analysis of Gal-1 expression in cell lysates from HL-1 cardiomyocytes cultured in the absence or presence of proinflammatory (IL-1 $\beta$, IL6 , IL-17, IFN- $\gamma$, TNF- $\alpha$ ) or anti-inflammatory (TGF$\beta 1, \mathrm{IL}-10)$ cytokines for 18 hours. Immunoreactive protein bands were semiquantified by densitometry and expressed as AU relative to $\beta$-actin. D: ELISA of Gal-1 secretion in serum-free supernatants from HL1 cardiomyocytes cultured in the absence or presence of proinflammatory (IL-1 $\beta$, IL-6, IL-17, TNF- $\alpha$, IFN- $\gamma$ ) or anti-inflammatory (TGF- $\beta 1$, IL-10) cytokines for 18 hours. E: Percentage of annexin- $\mathrm{V}^{+} \mathrm{HL}-$ 1 cells transfected with Gal-1 or scrambled (SCR) shRNA and cultured under normoxic or hypoxic conditions in the absence or presence of exogenous rGal-1 $(10 \mu \mathrm{g} / \mathrm{mL})$. F: Number of heartbeats per minute of primary cultures of cardiomyocytes did not differ between Lgals1 $^{-/-}$and WT mice. In primary cultures of cardiomyocytes from WT mice (G) and Lgals $1^{-/-}$mice (H) incubated with or without rGal-1 $(10 \mu \mathrm{g} / \mathrm{mL})$ in the absence or presence of isoproterenol $(1 \mu \mathrm{mol} / \mathrm{L})$, the number was significantly increased in the presence of isoproterenol, with or without rGal-1, compared with control. Data are expressed as means \pm SEM and are representative of two $(\mathbf{E}, \mathbf{F})$ or three $(\mathbf{A}-\mathbf{D}, \mathbf{G}, \mathbf{H})$ independent experiments. ${ }^{*} P<0.05$ versus control $(\mathbf{A}-\mathbf{D}, \mathbf{G}, \mathbf{H})$ or versus HL-1 cells cultured with medium alone $(\mathbf{E}) ;{ }^{* * *} P<0.001$ versus control. the number of heart beats in cardiomyocytes isolated from either WT or Lgals1 ${ }^{-1-}$ mice (Figure 2, G and H). These data indicate that Gal-1, either exogenously added or endogenously regulated, does not directly affect heart rate in vitro.

\section{Endogenous Gal-1 Controls Ventricular Function and Post-AMI Remodeling}

To investigate the relevance of endogenous Gal-1 in heart pathophysiology, we examined the role of this protein in baseline cardiac function and post-AMI ventricular remodeling in a mouse model of permanent coronary artery ligation characterized by marked cardiac dilation and severe LV systolic dysfunction. Importantly, the Lgals $^{-1-}$ and the age- and sex-matched WT mice had similar weights $\left(26.29 \pm 0.47 \mathrm{~g}\right.$ for $\mathrm{Lgalsl}^{-1-}$ versus $26.67 \pm 0.71 \mathrm{~g}$ for WT mice; $P=0.66$ ). At baseline echocardiography, Lgals $^{-1-}$ mice showed a $20 \%$ greater LVEDD, a $6 \%$ greater LVESD, and a 20\% lower LVFS, compared with WT mice (Figure 3, A and B), reflecting mild dilation associated with impaired systolic function. At 7 days after AMI, both groups showed adverse LV remodeling, reflected in LV enlargement and systolic dysfunction. The $\mathrm{Lgals}^{-1-}$ mice, however, showed a significantly greater LV enlargement than WT mice; the left ventricle is the anatomical substrate for heart failure. A trend toward reduced LV fractional shortening was also observed in $\mathrm{Lgals}^{-1-}$ mice, although the difference did not reach statistical significance (Figure 3, A-C).

\section{Gal-1 Controls Cardiac Inflammation in Vivo}

The broad anti-inflammatory activity of Gal- $1^{4,5}$ prompted us to investigate the ability of this endogenous lectin to control inflammatory cell infiltrates in cardiac tissue from Lgals $^{-1-}$ and WT mice after AMI and in sham-operated 
A

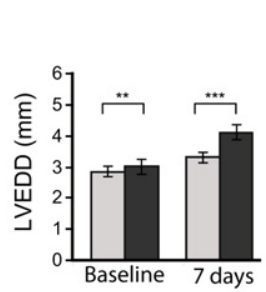

B

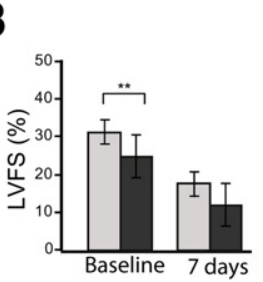

C

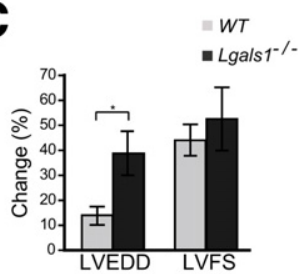

D

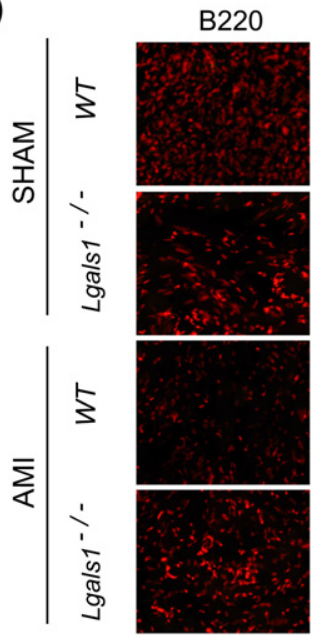

NK1.1

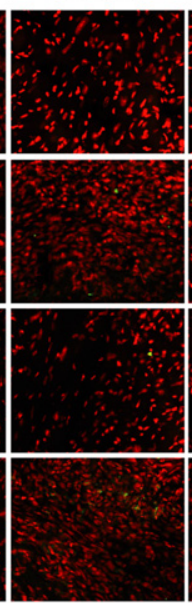

$\mathrm{F} 4 / 80$

$\mathrm{CD} 3$
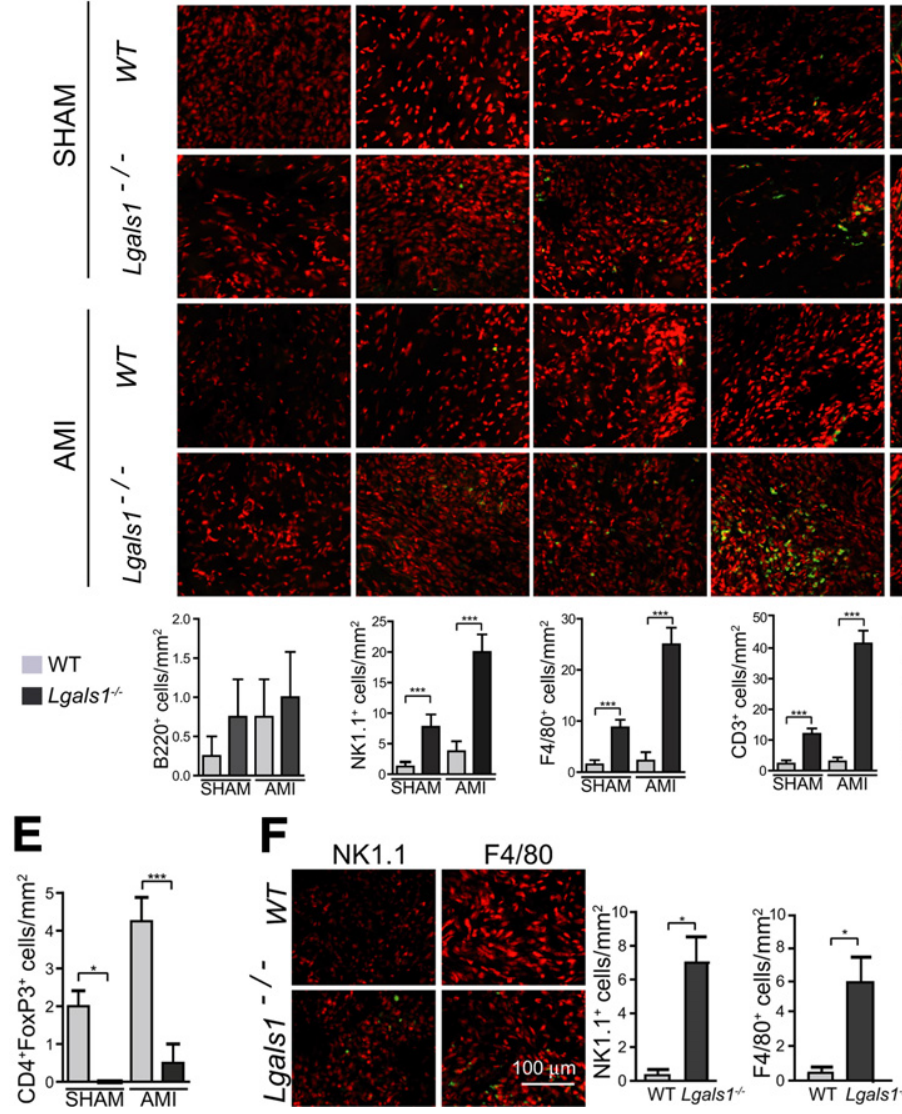

$\mathbf{F}$
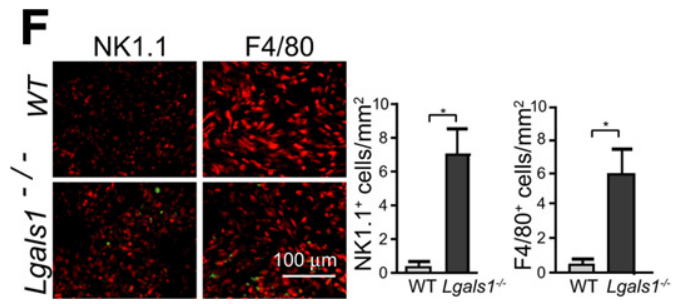

G

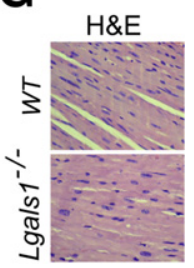

Figure 3 Endogenous Gal-1 controls ventricular remodeling after AMI through modulation of the inflammatory response. A-C: Left ventricular enddiastolic diameter (LVEDD) (A) was greater in Lgals $1^{-1-}$ than WT mice at baseline and at 7 days after myocardial infarction. LV fractional shortening (LVFS) (B) differed between genotypes only at baseline, with no significant difference at 7 days. The percentage of change (C) was significantly different between genotypes for LVEDD, but not for LVFS. D: Representative laser confocal micrographs of cardiac tissue from Lgals $1^{-/-}$or WT mice 7 days after AMI or sham surgery, with quantification of cell numbers. Tissues were immunostained for B cells (B220), NK cells (NK1.1), macrophages (F4/80), T cells (CD3), blood vessels (CD31) (all in green), and for propidium iodide (red). E: Number of $\mathrm{CD}^{+}{ }^{+} \mathrm{FoxP}_{3}{ }^{+} \mathrm{T}$ regulatory $\left(\mathrm{T}_{\text {reg }}\right)$ cells $/ \mathrm{mm}^{2}$ in cardiac tissue from $\mathrm{Lgals}^{-/-}$or WT mice 7 days after AMI or sham surgery. F: Representative laser confocal micrographs of cardiac tissue from Lgals1 $^{-/-}$or WT mice at baseline without any intervention, with quantification of cell numbers. Tissues were immunostained for NK cells (NK1.1; green) and macrophages (F4/80; green), and for propidium iodide (red). No changes were observed in $\mathrm{B}_{220^{+}} \mathrm{B}$ cells and $\mathrm{CD}^{+} \mathrm{T}$ cells at baseline (data not shown). G: H\&E staining of cardiac tissue from Lgals $1^{-I^{-}}$or WT mice at baseline showed no significant histological alterations. Data are expressed as means \pm SEM. $n=6$ per genotype. ${ }^{*} P<0.05,{ }^{* *} P<0.01$, and ${ }^{* * *} P<$ 0.001 . Scale bar $=100 \mu \mathrm{m}$ (D and $\mathbf{F})$. Original magnification, $\times 40(\mathbf{G})$. animals. Although sham-operated WT mice showed no or minimal cardiac inflammation, sham-operated Lgals $^{-1-}$ mice showed prominent inflammatory cell infiltrates, composed mainly of $\mathrm{CD}^{+}{ }^{+} \mathrm{T}$ cells, $\mathrm{F} 4 / 80^{+}$macrophages, and NK1.1 $1^{+}$natural killer (NK) cells (Figure 3D). Notably, cardiac inflammation was even more pronounced 7 days after experimental AMI in $\mathrm{Lgals}^{-1-}$ mice, but not in WT mice (Figure 3D). Moreover, cardiac tissue from $\mathrm{Lgalsl}^{-1-}$ mice also showed lower numbers of $\mathrm{CD}^{+} \mathrm{FoxP}^{+} \mathrm{T}$ regulatory $\left(\mathrm{T}_{\text {reg }}\right)$ cells, compared with WT mice in sham-operated mice and after experimental AMI (Figure 3E). Interestingly, we also found, although to a much lesser extent, increased frequency of intramyocardial innate immune cells (macrophages and NK cells) in Lgals ${ }^{-1-}$ mice compared with WT mice at baseline in the absence of any intervention (Figure 3F), suggesting that Gal-1 deficiency imposes an increased predisposition toward the development of cardiac inflammation. However, we observed no histological alterations in myocardial structure (Figure 3G), nor in interstitial or perivascular collagen (data not shown). Thus, Gal-1 deficiency leads to development of a cardiac inflammatory response that is further enhanced after AMI, resulting in impaired ventricular remodeling.

Given the ability of Gal-1 to modulate angiogenesis in tumor settings ${ }^{7}$ and the role of neovascularization in heart pathophysiology, ${ }^{21}$ we also examined the effects of Gal-1 deficiency in myocardium angiogenesis. We found no statistically significant differences in the number or caliber of $\mathrm{CD} 31^{+}$blood vessels within the peri-infarct area of $\mathrm{Lgals}^{-1-}$ mice versus WT mice (Figure 3D), suggesting that endogenous Gal-1 does not considerably affect myocardium angiogenesis in vivo. Furthermore, we found no considerable difference in the expression of matrix metalloproteinase-9 (MMP-9), a critical enzyme that contributes to ventricular remodeling after AMI, in LgalsI ${ }^{-1-}$ mice versus WT mice (data not shown). Taken together, these data suggest that endogenous Gal-1 contributes to cardiac homeostasis by selectively modulating myocardial inflammation. 


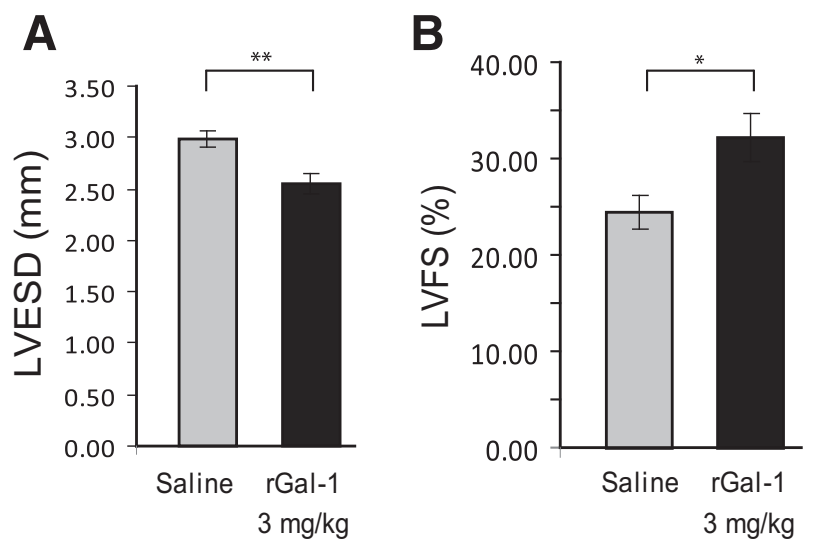

Figure 4 Gal-1 treatment attenuates cardiac damage in reperfused AMI in mice. CD-1 mice were subjected to surgical transient coronary artery ligation for 30 minutes, followed by reperfusion for 7 days. At time of reperfusion, mice were randomly assigned to treatment with $\mathrm{rGal}-1(3 \mathrm{mg} /$ $\mathrm{kg}$ i.p.) or saline control (matching volume). LVESD was significantly decreased (A) and LVFS was significantly increased (B) under rGal-1 treatment. Data are expressed as means \pm SEM. $n=6$ mice per group. ${ }^{*} P<0.05,{ }^{* *} P<0.01$.

\section{Gal-1 Treatment Attenuates Cardiac Damage in Reperfused AMI}

The ability of endogenous Gal-1 to limit post-AMI ventricular remodeling through inhibition of cardiac inflammation prompted us to examine whether exogenous administration of this lectin could prevent cardiac damage after reperfused AMI in WT mice, using a clinically relevant model of the disease. Before surgery, all mice had similar ventricular size and systolic function. A single dose of rGal-1 (3 mg/kg i.p.) 3 minutes before reperfusion prevented LV enlargement and preserved systolic function as shown by LVFS percentage, compared with control mice receiving saline solution (Figure 4). Thus, administration of rGal-1 attenuates cardiac dysfunction in reperfused AMI, which suggests a novel molecular target to prevent cardiac failure.

\section{Discussion}

Despite considerable evidence of the role of Gal-1 in acute and chronic inflammation, immunoregulation, and angiogenesis, ${ }^{4}$ the involvement of this endogenous lectin in cardiac pathophysiology remains obscure. Recent observations showed that Gal-1 is expressed by cardiomyocytes in an organized pattern colocalizing with sarcomeric actin on I bands. ${ }^{12}$ In addition, Gal-1 is considerably up-regulated in inflammatory microenvironments ${ }^{4,5}$ and is a key component of the hypoxia-regulated transcriptome, ${ }^{11}$ suggesting a potential role for this glycan-binding protein in post-AMI ventricular remodeling and heart failure.

In the present study, Gal-1 was expressed at low levels in normal mouse heart, but was considerably up-regulated (approximately sevenfold) 7 days after AMI, suggesting an essential role for this lectin in controlling cardiac inflammation after AMI. This expression pattern is in accord with previous reports describing a peak of infiltrating dendritic cells, lymphocytes, and macrophages after AMI in the same model, ${ }^{14,15}$ and is consistent with the peak of Gal-1 expression observed in the brain after ischemic stroke. ${ }^{22} \mathrm{In}$ the present study, Gal-1 expression was found in cardiomyocytes and inflammatory infiltrates of the peri-infarct area, and was considerably up-regulated in cardiomyocytes exposed to hypoxic microenvironments or proinflammatory cytokines. These stimuli, which represent a hallmark of AMI, ${ }^{15,23}$ might induce Gal-1 expression to limit myocardial inflammation, restore cardiac homeostasis, and prevent adverse ventricular remodeling. In support of this assumption, ggalsI $^{-1-}$ mice also showed a cardiac inflammatory response at baseline and when sham-operated, characterized by greater numbers of NK cells and macrophages, whereas cardiomyocyte morphology and collagen structure were preserved. In addition, no significant abnormalities were observed on the baseline electrocardiogram, which showed normal sinus rhythm without any conduction abnormality or ST segment shifts in all cases (data not shown). Increased inflammatory response observed in $\mathrm{LgalsI}^{-1-}$ mice was further exacerbated after AMI, compared with WT mice, leading to impaired ventricular remodeling after 7 days. Taken together, these results suggest an important role for Gal-1 in cardiac homeostasis.

In support of our findings, Lgals1 ${ }^{-1-}$ mice show augmented Th1 and Th17 responses, enhanced susceptibility to autoimmune inflammation, and increased fetal loss due to impaired fetomaternal tolerance. ${ }^{10,24}$ However, despite baseline cardiomyopathy, the life span of these mice appears to be normal, suggesting a compensatory effect of other mediators (probably other members of the galectan family) in the resolution of cardiac inflammatory response. Moreover, although we found no structural alterations in cardiomyocytes at the microscopic level, Gal-1 colocalization with sarcomeric actin on I bands in myocytes ${ }^{12}$ suggests that this endogenous lectin could play additional roles in myocyte contractility. Further studies are warranted to examine these alternative nonimmunological mechanisms. Nevertheless, in the present study we found a state of myocarditis mediated by greater numbers of $\mathrm{T}$ cells, macrophages, and NK cells and reduced frequency of $\mathrm{T}_{\text {reg }}$ cells that could explain, at least in part, the phenotype observed in $\mathrm{Lgals}^{-1-}$ mice after AMI.

Supporting these findings and consistent with the role of Gal-1 in T cell tolerance, ${ }^{4}$ recent studies demonstrated that a $\mathrm{T}$ cell-mediated autoimmune disease due to altered thymic selection underlies the pathogenesis of dilated cardiomyopathy in mice and humans. ${ }^{25}$ Interestingly, and consistent with the up-regulated expression of Gal-1 after mouse experimental AMI, we found that this endogenous lectin was also up-regulated in cardiac tissue from patients with end-stage heart failure, suggesting its biological relevance in human cardiac pathology. Gal-1 was also up-regulated in cardiac tissue from patients with Chagas' disease 
cardiomyopathy. ${ }^{26}$ Thus, Gal-1 may serve as a key component of the homeostatic and proresolving machinery that contributes to dampening the inflammatory response during cardiac healing.

In the present study, we found that mice lacking Gal-1 showed LV enlargement and reduction in systolic function at baseline. Seven days after AMI, absence of Gal-1 led to increased ventricular dilation associated with a trend toward reduced systolic function. The lack of statistical significance in LVFS at 7 days despite improved remodeling could be, at least in part, due to the short follow-up period (ie, 7 days). At early stages, the initial increase of LV volume after AMI serves the purpose of preserving the stroke volume, whereas late LV dilation becomes a mechanism of reduced ejection fraction and progression to heart failure. A similar effect was observed when mice were treated with an inhibitor of myeloid differentiation factor 88 (MyD88). ${ }^{27}$ Notably, Lgals1 ${ }^{-1-}$ mice showed a greater LVEDD than WT mice after AMI, reflecting impaired cardiac remodeling. Adverse remodeling has been associated with greater Th1- and Th17-mediated myocardial inflammation. ${ }^{28,29}$ Patients with acute coronary syndrome showed a significant increase in the frequency of peripheral Th17 cells and Th17-related cytokines (IL-17, IL-6, and IL-23), and evidenced a considerable decrease in $T_{\text {reg }}$ cell number and $\mathrm{T}_{\text {reg }}$-related cytokines (IL-10 and TGF- $\beta 1$ ), compared with control patients. ${ }^{29}$ Moreover, impaired recruitment of $\mathrm{T}_{\text {reg }}$ cells led to adverse remodeling after AMI in mice lacking the $\mathrm{CC}$ chemokine receptor (CCR)5 signaling. ${ }^{30}$ In contrast, targeted deletion of CCR2, a receptor that mediates leukocyte chemoattraction during coronary heart disease, attenuated LV remodeling after experimental AMI through inhibition of TNF- $\alpha$, angiogenesis, and MMP activity. ${ }^{31}$

Interestingly, we found that Th17- and Th1-type cytokines up-regulate Gal-1, and Lgals1 ${ }^{-1-}$ mice showed increased inflammatory response and decreased $\mathrm{T}_{\text {reg }}$ cell frequency, suggesting that alterations in the expression, secretion, or functional activity of this endogenous lectin could influence the $\mathrm{Th} 17 / \mathrm{T}_{\text {reg }}$ cell balance at the onset of acute coronary events. In this regard, Gal-1 has been shown to be a key mediator of the immunosuppressive activity of $\mathrm{CD} 4{ }^{+} \mathrm{CD} 25^{+} \mathrm{FoxP}^{+}{ }^{+} \mathrm{T}_{\text {reg }}$ cells, ${ }^{32}$ to drive the expansion of IL-10-producing $\mathrm{T}_{\text {reg }}$ cells in vivo, ${ }^{33}$ and to induce the differentiation of $\mathrm{T}$ regulatory type-1 ( $\mathrm{Tr} 1)$ cells either directly through modulation of the c-Maf/aryl hydrocarbon receptor pathway ${ }^{34}$ or indirectly through the generation of IL-27-producing tolerogenic dendritic cells. ${ }^{35}$ In this regard, lack of regulatory dendritic cells led to sustained inflammation, adverse remodeling, prolonged extracellular matrix degradation, and increased angiogenesis in an experimental model of AMI. ${ }^{36}$ In the present study, we could detect no significant differences in the number of blood vessels or the expression of MMP-9 in the peri-infarct area, suggesting that the inflammatory response is a major target of Gal-1 during heart failure. This anti-inflammatory activity of
Gal-1 is in accord with previous findings showing the role of this lectin in the resolution of acute inflammation and inhibition of innate immunity. ${ }^{37,38,39}$

In the present study, we first tested the effects of Gal-1 in a model of severe nonreperfused AMI that resembles a condition of no reperfusion (late comers) or incomplete reperfusion (no reflow), commonly observed in patients with AMI and associated with worse prognosis and progression to heart failure. ${ }^{40}$ The reperfused AMI, however, is the most commonly used model in the mouse, and most patients presenting with AMI are subjected to a reperfusion strategy. The effects of endogenous Gal-1 in heart pathophysiology prompted us to validate the effects of exogenous rGal-1 in this clinically relevant ischemiareperfusion model. Using this approach, a single dose of rGal-1 ( $3 \mathrm{mg} / \mathrm{kg}$ i.p. $)$ at the time of reperfusion showed powerful cardioprotective effects, preventing LV enlargement and systolic dysfunction. In this regard, ischemia and reperfusion usually lead to a brief but more pronounced inflammatory response that contributes to cardiac damage. ${ }^{15}$ Apoptosis is an important mechanism implicated in cardiomyocyte ischemia-reperfusion injury. ${ }^{41}$ Although we could find no substantial effects of Gal-1 on hypoxiainduced apoptosis in vitro, further studies are warranted to study the effects of Gal-1 on ischemic necrosis.

Importantly, although our findings highlight a possible cardioprotective effect of Gal-1 through regulation of myocardial inflammation, caution is needed before translation to clinical practice, because this endogenous lectin can also trigger other biological effects, including platelet aggregation and activation. ${ }^{42}$ Moreover, the Gal- 1 protective effects should be considered in light of previous findings demonstrating that Gal-2, another prototype member of the galectin family, can confer risk of myocardial infarction in selected Japanese but not other populations. ${ }^{43,44}$ Moreover, Gal-3, a chimera-type member of the galectin family, has been proposed as a powerful biomarker of disease progression in patients with heart failure, ${ }^{45}$ suggesting that individual members of the galectin family may play distinct and often opposing roles in the control of acute coronary disease. Further studies are warranted to investigate the regulated expression and function of different members of the galectin family in experimental models of AMI.

In summary, our data identify a key function of Gal-1 in normal cardiac homeostasis and highlight the protective role of this endogenous lectin in postinfarction remodeling through negative regulation of the inflammatory response. Thus, therapeutic administration of Gal-1 or modulation of its expression in cardiac tissue may represent a potential novel strategy to prevent heart failure after AMI.

\section{References}

1. National Heart, Lung, and Blood Institute: Morbidity and Mortality: 2012 Chart Book on Cardiovascular and Lung Diseases. Bethesda, MD, NIH, 2012 
2. Braunwald E: Shattuck lecture-cardiovascular medicine at the turn of the millennium: triumphs, concerns, and opportunities. N Engl J Med 1997, 337:1360-1369

3. Velagaleti RS, Pencina MJ, Murabito JM, Wang TJ, Parikh NI, D'Agostino RB, Levy D, Kannel WB, Vasan RS: Long-term trends in the incidence of heart failure after myocardial infarction. Circulation 2008, 118:2057-2062

4. Rabinovich GA, Croci DO: Regulatory circuits mediated by lectinglycan interactions in autoimmunity and cancer. Immunity 2012, 36: 322-335

5. Camby I, Le Mercier M, Lefranc F, Kiss R: Galectin-1: a small protein with major functions. Glycobiology 2006, 16:137R-157R

6. Liu FT, Rabinovich GA: Galectins: regulators of acute and chronic inflammation. Ann N Y Acad Sci 2010, 1183:158-182

7. Thijssen VL, Postel R, Brandwijk RJ, Dings RP, Nesmelova I, Satijn S, Verhofstad N, Nakabeppu Y, Baum LG, Bakkers J, Mayo KH, Poirier F, Griffioen AW: Galectin-1 is essential in tumor angiogenesis and is a target for antiangiogenesis therapy. Proc Natl Acad Sci USA 2006, 103:15975-15980

8. Pace KE, Lee C, Stewart PL, Baum LG: Restricted receptor segregation into membrane microdomains occurs on human $\mathrm{T}$ cells during apoptosis induced by galectin-1. J Immunol 1999, 163:3801-3811

9. Rabinovich GA, Daly G, Dreja H, Tailor H, Riera CM, Hirabayashi J, Chernajovsky Y: Recombinant galectin-1 and its genetic delivery suppress collagen-induced arthritis via T cell apoptosis. J Exp Med 1999, 190:385-398

10. Toscano MA, Bianco GA, Ilarregui JM, Croci DO, Correale J, Hernandez JD, Zwirner NW, Poirier F, Riley EM, Baum LG, Rabinovich GA: Differential glycosylation of TH1, TH2 and TH-17 effector cells selectively regulates susceptibility to cell death. Nat Immunol 2007, 8:825-834

11. Le QT, Shi G, Cao H, Nelson DW, Wang Y, Chen EY, Zhao S, Kong C, Richardson D, O’Byrne KJ, Giaccia AJ, Koong AC: Galectin1: a link between tumor hypoxia and tumor immune privilege. J Clin Oncol 2005, 23:8932-8941

12. Dias-Baruffi M, Stowell SR, Song SC, Arthur CM, Cho M, Rodrigues LC, Montes MA, Rossi MA, James JA, McEver RP, Cummings RD: Differential expression of immunomodulatory galectin-1 in peripheral leukocytes and adult tissues and its cytosolic organization in striated muscle. Glycobiology 2010, 20:507-520

13. Seropian IM, Abbate A, Toldo S, Harrington J, Smithson L, Ockaili R, Mezzaroma E, Damilano F, Hirsch E, Van Tassell BW: Pharmacological inhibition of phosphoinositide 3-kinase gamma (PI3Kgamma) promotes infarct resorption and prevents adverse cardiac remodeling after myocardial infarction in mice. J Cardiovasc Pharmacol 2010, 56:651-658

14. Naito K, Anzai T, Sugano Y, Maekawa Y, Kohno T, Yoshikawa T, Matsuno K, Ogawa S: Differential effects of GM-CSF and G-CSF on infiltration of dendritic cells during early left ventricular remodeling after myocardial infarction. J Immunol 2008, 181:5691-5701

15. Vandervelde S, van Amerongen MJ, Tio RA, Petersen AH, van Luyn MJ, Harmsen MC: Increased inflammatory response and neovascularization in reperfused vs. non-reperfused murine myocardial infarction. Cardiovasc Pathol 2006, 15:83-90

16. Schiller NB, Shah PM, Crawford M, DeMaria A, Devereux R, Feigenbaum H, Gutgesell H, Reichek N, Sahn D, Schnittger I: Recommendations for quantitation of the left ventricle by twodimensional echocardiography: American Society of Echocardiography Committee on Standards. Subcommittee on Quantitation of Two-Dimensional Echocardiograms. J Am Soc Echocardiogr 1989, 2: 358-367

17. Juszczynski P, Ouyang J, Monti S, Rodig SJ, Takeyama K, Abramson J, Chen W, Kutok JL, Rabinovich GA, Shipp MA: The AP1-dependent secretion of galectin-1 by Reed Sternberg cells fosters immune privilege in classical Hodgkin lymphoma. Proc Natl Acad Sci USA 2007, 104:13134-13139

18. Claycomb WC, Lanson NA Jr, Stallworth BS, Egeland DB, Delcarpio JB, Bahinski A, Izzo NJ Jr: HL-1 cells: a cardiac muscle cell line that contracts and retains phenotypic characteristics of the adult cardiomyocyte. Proc Natl Acad Sci USA 1998, 95:2979-2984

19. Aoki MP, Guiñazú NL, Pellegrini AV, Gotoh T, Masih DT, Gea S: Cruzipain, a major Trypanosoma cruzi antigen, promotes arginase-2 expression and survival of neonatal mouse cardiomyocytes. Am J Physiol Cell Physiol 2004, 286:C206-C212

20. Swedberg K, Komajda M, Böhm M, Borer JS, Ford I, DubostBrama A, Lerebours G, Tavazzi L: SHIFT Investigators: Ivabradine and outcomes in chronic heart failure (SHIFT): a randomised placebocontrolled study. Lancet 2010, 376:875-885

21. Van der Laan AM, Piek JJ, van Royen N: Targeting angiogenesis to restore the microcirculation after reperfused MI. Nat Rev Cardiol 2009, 6:515-523

22. Ishibashi S, Kuroiwa T, Sakaguchi M, Sun L, Kadoya T, Okano H, Mizusawa H: Galectin-1 regulates neurogenesis in the subventricular zone and promotes functional recovery after stroke. Exp Neurol 2007, 207:302-313

23. Sun M, Dawood F, Wen WH, Chen M, Dixon I, Kirshenbaum LA, Liu PP: Excessive tumor necrosis factor activation after infarction contributes to susceptibility of myocardial rupture and left ventricular dysfunction. Circulation 2004, 110:3221-3228

24. Blois SM, Ilarregui JM, Tometten M, Garcia M, Orsal AS, CordoRusso R, Toscano MA, Bianco GA, Kobelt P, Handjiski B, Tirado I, Markert UR, Klapp BF, Poirier F, Szekeres-Bartho J, Rabinovich GA, Arck PC: A pivotal role for galectin-1 in fetomaternal tolerance [Erratum appeared in Nat Med 2009, 15:584]. Nat Med 2007, 13: $1450-1457$

25. Lv H, Havari E, Pinto S, Gottumukkala RV, Cornivelli L, Raddassi K, Matsui T, Rosenzweig A, Bronson RT, Smith R, Fletcher AL, Turley SJ, Wucherpfennig K, Kyewski B, Lipes MA: Impaired thymic tolerance to alpha-myosin directs autoimmunity to the heart in mice and humans. J Clin Invest 2011, 121:1561-1573

26. Giordanengo L, Gea S, Barbieri G, Rabinovich GA: Anti-galectin-1 autoantibodies in human Trypanosoma cruzi infection: differential expression of this beta-galactoside-binding protein in cardiac Chagas' disease. Clin Exp Immunol 2001, 124:266-273

27. Van Tassell BW, Seropian IM, Toldo S, Salloum FN, Smithson L, Varma A, Hoke NN, Gelwix C, Chau V, Abbate A: Pharmacologic inhibition of myeloid differentiation factor 88 (MyD88) prevents left ventricular dilation and hypertrophy after experimental acute myocardial infarction in the mouse [Erratum in J Cardiovasc Pharmacol 2011, 57:272. Dosage error in article text.]. J Cardiovasc Pharmacol 2010, 55:385-390

28. Zhao Z, Wu Y, Cheng M, Ji Y, Yang X, Liu P, Jia S, Yuan Z: Activation of Th17/Th1 and Th1, but not Th17, is associated with the acute cardiac event in patients with acute coronary syndrome. Atherosclerosis 2011, 217:518-524

29. Cheng X, Yu X, Ding YJ, Fu QQ, Xie JJ, Tang TT, Yao R, Chen Y, Liao YH: The Th17/Treg imbalance in patients with acute coronary syndrome [Erratum appeared in Clin Immunol 2009, 133:447]. Clin Immunol 2008, 127:89-97

30. Dobaczewski M, Xia Y, Bujak M, Gonzalez-Quesada C, Frangogiannis NG: CCR5 signaling suppresses inflammation and reduces adverse remodeling of the infarcted heart, mediating recruitment of regulatory T cells. Am J Pathol 2010, 176:2177-2187

31. Kaikita K, Hayasaki T, Okuma T, Kuziel WA, Ogawa H, Takeya M: Targeted deletion of CC chemokine receptor 2 attenuates left ventricular remodeling after experimental myocardial infarction. Am J Pathol 2004, 165:439-447

32. Garín MI, Chu CC, Golshayan D, Cernuda-Morollón E, Wait R, Lechler RI: Galectin-1: a key effector of regulation mediated by CD4+CD25+ T cells. Blood 2007, 109:2058-2065

33. Toscano MA, Commodaro AG, Ilarregui JM, Bianco GA, Liberman A, Serra HM, Hirabayashi J, Rizzo LV, Rabinovich GA: Galectin-1 suppresses autoimmune retinal disease by promoting concomitant Th2and $\mathrm{T}$ regulatory-mediated anti-inflammatory responses. J Immunol 2006, 176:6323-6332 
34. Cedeno-Laurent F, Opperman M, Barthel SR, Kuchroo VK, Dimitroff CJ: Galectin-1 triggers an immunoregulatory signature in Th cells functionally defined by IL-10 expression. J Immunol 2012, 188:3127-3137

35. Ilarregui JM, Croci DO, Bianco GA, Toscano MA, Salatino M, Vermeulen ME, Geffner JR, Rabinovich GA: Tolerogenic signals delivered by dendritic cells to $\mathrm{T}$ cells through a galectin-1-driven immunoregulatory circuit involving interleukin 27 and interleukin 10. Nat Immunol 2009, 10:981-991

36. Anzai A, Anzai T, Nagai S, Maekawa Y, Naito K, Kaneko H, Sugano Y, Takahashi T, Abe H, Mochizuki S, Sano M, Yoshikawa T, Okada Y, Koyasu S, Ogawa S, Fukuda K: Regulatory role of dendritic cells in postinfarction healing and left ventricular remodeling. Circulation 2012, 125:1234-1245

37. La M, Cao TV, Cerchiaro G, Chilton K, Hirabayashi J, Kasai K, Oliani SM, Chernajovsky Y, Perretti M: A novel biological activity for galectin-1: inhibition of leukocyte-endothelial cell interactions in experimental inflammation. Am J Pathol 2003, 163:1505-1515

38. Rabinovich GA, Sotomayor CE, Riera CM, Bianco I, Correa SG: Evidence of a role for galectin-1 in acute inflammation. Eur J Immunol 2000, 30:1331-1339

39. Sato S, St-Pierre C, Bhaumik P, Nieminen J: Galectins in innate immunity: dual functions of host soluble beta-galactoside-binding lectins as damage-associated molecular patterns (DAMPs) and as receptors for pathogen-associated molecular patterns (PAMPs). Immunol Rev 2009, 230:172-187

40. Abbate A, Kontos MC, Biondi-Zoccai GG: No-reflow: the next challenge in treatment of ST-elevation acute myocardial infarction. Eur Heart J 2008, 29:1795-1797

41. Ho FY, Tsang WP, Kong SK, Kwok TT: The critical role of caspases activation in hypoxia/reoxygenation induced apoptosis. Biochem Biophys Res Commun 2006, 345:1131-1137

42. Pacienza N, Pozner RG, Bianco GA, D'Atri LP, Croci DO, Negrotto S, Malaver E, Gómez RM, Rabinovich GA, Schattner M: The immunoregulatory glycan-binding protein galectin-1 triggers human platelet activation. FASEB J 2008, 22:1113-1123

43. Ozaki K, Inoue K, Sato H, Iida A, Ohnishi Y, Sekine A, Sato H, Odashiro K, Nobuyoshi M, Hori M, Nakamura Y, Tanaka T: Functional variation in LGALS2 confers risk of myocardial infarction and regulates lymphotoxin-alpha secretion in vitro. Nature 2004, 429: $72-75$

44. Mangino M, Braund P, Singh R, Steeds R, Thompson JR, Channer K, Samani NJ: LGALS2 functional variant rs7291467 is not associated with susceptibility to myocardial infarction in Caucasians. Atherosclerosis 2007, 194:112-115

45. Yanavitski M, Givertz MM: Novel biomarkers in acute heart failure. Curr Heart Fail Rep 2011, 8:206-211 